\title{
Case finding of Influenza A(H1N1)2009 in Belgium in the early pandemic
}

\author{
by \\ Quoilin $\mathrm{S}^{1}$, Thomas $\mathrm{I}^{1}$, Gérard $\mathrm{C}^{1}$, Brochier $\mathrm{B}^{1}$, Bots $\mathrm{J}^{2}$, Lokietek $\mathrm{S}^{3}$, \\ Robesyn $\mathrm{E}^{4}$, Wuillaume $\mathrm{F}^{1}$, Muyldermans $\mathrm{G}^{1}$
}

\section{Introduction}

As soon as a possible worldwide spread of a new Influenza A virus was announced, Belgian health authorities decided to intervene in order to delay the spread of the new virus in the population $(1,2)$.

The delaying strategy started on 26 April 2009 based on a systematic case finding of Influenza $A(H 1 N 1) 2009$ in travellers returning from affected areas and their contacts for the purpose of taking individual control measures.

From 13 July onwards, the Interministerial Influenza Coordination Committee announced the switch to a mitigation phase (1). This required appropriate surveillance of influenza-like illnesses. The sentinel general practitioners (SGPs) network for seasonal influenza was reinforced and took over the systematic case finding system (3).

We report on the enhanced case-based surveillance of the first cases of Influenza A(H1N1)2009 up to 13 July 2009 and the subsequent mitigation phase till the start (3 October 2009) of the classical seasonal flu period.

\section{Method}

A procedure for case and contact management was adapted from the existing preparedness plan for Influenza A/H5N1. Case finding was based on the case definition for possible cases that included clinical and epidemiological criteria. An enlargement to a definition for a suspected case was made in order to allow sampling among patients who did not meet all criteria.

The case finding procedure was communicated to medical doctors and made available on the dedicated reference website (www.influenza.be).

During the containment phase, each suspected case was notified by the medical doctor to the health inspector of the respective region. Together with the medical epidemiologist on call of the Scientific Institute of Public Health (WIV-ISP), the decision was made to take or

\footnotetext{
1 Scientific Institute of Public Health, Brussels, Belgium

2 Health Inspectorate, Brussels Region, Brussels, Belgium

3 Belgian Health Inspectorate French Community, Mons, Belgium

4 Flemish Agency for Care and Health, Brussels, Belgium sophie.quoilin@wiv-isp.be
} 
not to take a sample. Sample kits and questionnaires were made available to all clinical laboratories and if necessary, immediately delivered to general practitioners by the National Centre for Influenza (NIC) of WIV-ISP (4), where samples were analysed daily. Each day, the medical doctor on call at the former Epidemiology Unit of the WIV-ISP informed the prescribers and brought all epidemiological information together with final diagnoses in order to inform health authorities allowing them to take protective measures according to the procedure.

During the mitigation phase, the SGP network was enhanced in order to gather the necessary information allowing the epidemiological follow-up, leaving again individual diagnosis based on clinical picture only. However individual laboratory diagnoses were still performed by the NIC, as by others labs where the diagnose capacity was delocalised, responding to the time needed for adaptation from one strategy to another or to the necessity in some cases to have a confirmed diagnose (e.g. pregnant women, chronically ill patients, patients with unfavourable evolution). This information was still gathered and integrated in the weekly report to health authorities. During the mitigation phase, considering that the virus was circulating in Belgium, the epidemiological criterion of travelling to an affected area was removed from the case definition. A possible case was therefore based on clinical criteria only.

\section{Results}

From 26 April (week 17) up to 3 October 2009 (week 40), samples of 875 patients were tested in the lab. According to the Influenza Preparedness Plan, only patients fulfilling criteria for a possible case should have been selected for laboratory testing. The fact that only $38 \%$ of patients tested complied with the definition of a possible case, indicates that the recruitment of cases for lab testing was not specific.

From 26 April to 13 July 2009 (containment phase), 123 (20\%) out of 614 collected samples from suspected Influenza A(H1N1)2009 cases were confirmed by RT-PCR while from 14 July up to end September 2009 (mitigation phase) a similar proportion of 50 patients (19\%) were diagnosed as Influenza A(H1N1)2009 cases among 261 tests performed (Figure 1).

Seasonal flu also affected 16 cases, including 15 Influenza $A(H 3 N 2)$ virus and 1 Influenza $B$ virus ( $1.8 \%$ of tested patients) and among them, 15 were identified during the containment phase.

In Belgium, the first positive case of Influenza A(H1N1)2009 was identified from a sample taken on 12 May during week 20. After 8 weeks a total of 123 positive cases for Influenza $A(H 1 N 1) 2009$ were laboratory confirmed in Belgium. The official number of cases for this period reached 126 patients since one case was registered by the SGP network and two cases remained probable cases. These two symptomatic cases were close contacts of confirmed cases but no samples were taken for laboratory confirmation because the patients were young children. 
Figure 1. Number of lab tests by week and by result, week 17-40, 2009, Belgium.

Other influenza includes the unsubtyped influenza A samples

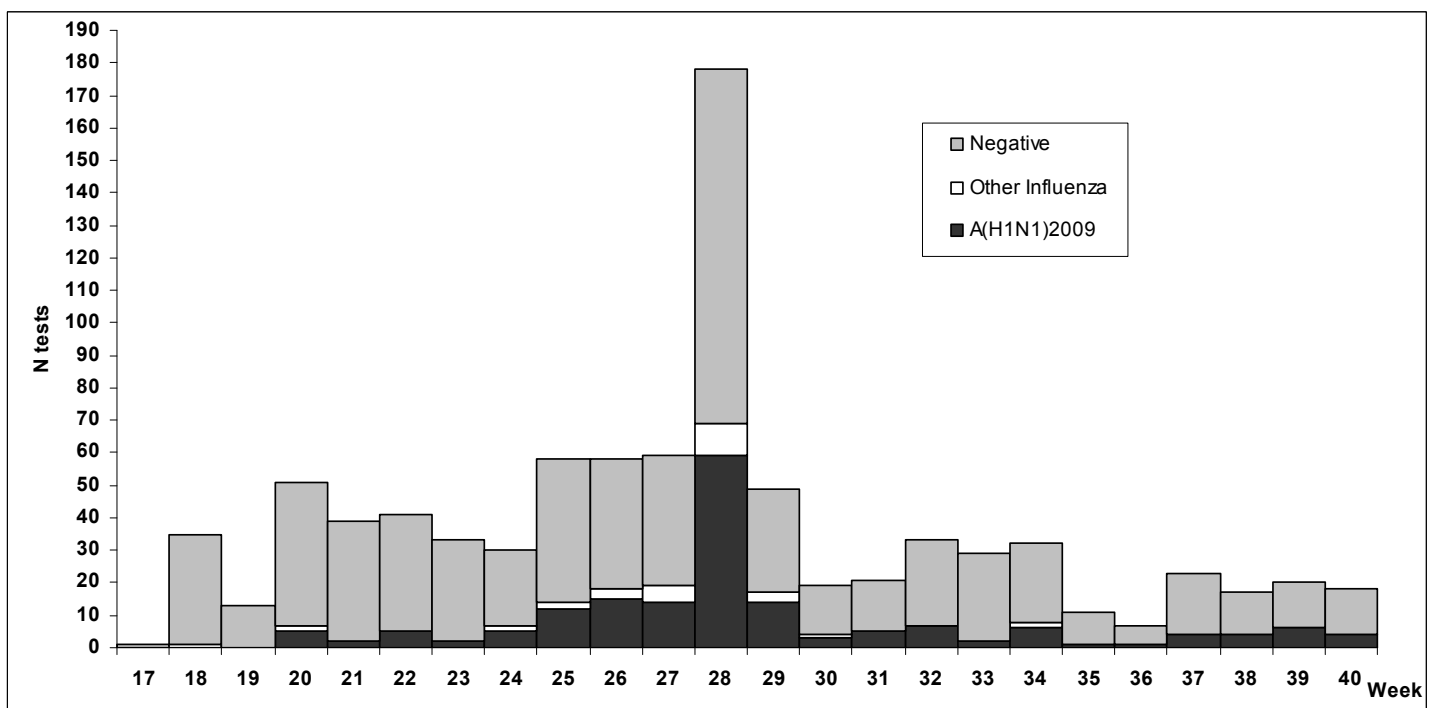

A peak was observed in week 28 when cases related to two outbreaks were detected with 13 confirmed cases among participants of a rock festival in Werchter (5) and 15 confirmed cases from a language summer school. Afterwards a constant and low viral activity was observed during the summer holiday period.

The first death was reported in week 30 and the second one in week 38, both during the mitigation period. For both phases, 176 cases were diagnosed as Influenza A(H1N1)2009 and among them males were more affected than females (sex ratio $(\mathrm{M} / \mathrm{F})=1.5)$. The median age of the Influenza $A(H 1 N 1) 2009$ cases was 21 years (range 1-59), significantly lower $(p<0.01)$ than the median age among tested patients (32 years) and still lower than the median age for seasonal influenza affected patients (41 years).

Figure 2. Number of lab tests per 100,000, by age group and by result, week 17-40, 2009, Belgium. Other influenza includes the unsubtyped influenza A samples

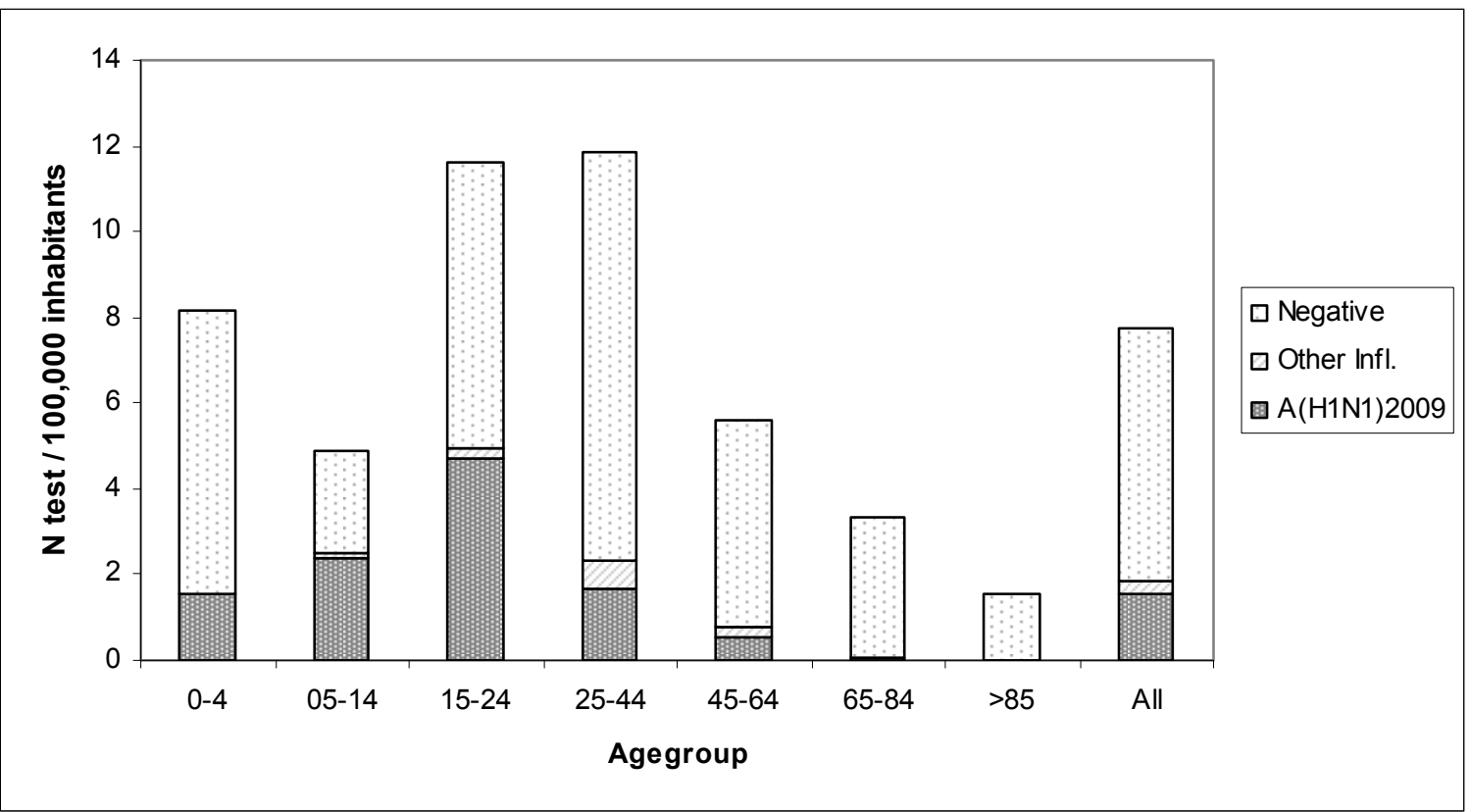


The detection rate of Influenza A(H1N1)2009 in Belgium between week 17 and 40 was about 1.6 cases by 100,000 inhabitants. The most affected age group by Influenza $A(H 1 N 1) 2009$ was 15-24 years (Figure 2) with 4.7 confirmed cases per 100,000. No reported cases were older than 59 years.

The majority of cases were residents of the provinces Antwerp (Antwerpen), Flemish Brabant (Vlaams-Brabant) and the Brussels-Capital Region (Table 1). Except in the Brussels Region, a decrease of the number of tests and of the incidence of Influenza A(H1N1)2009 was observed between the two phases. During the second phase the highest incidence remained in the province of Antwerp and the Brussels Region; both with densely and internationally populated cities.

Table 1. Number of probable and confirmed cases and other results of lab tests, proportion by 100,000 inhabitants, by province, week 17-40/2009, Belgium

\begin{tabular}{|c|c|c|c|c|c|c|}
\hline & $\begin{array}{l}\text { Probable and } \\
\text { confirmed } \\
\text { A(H1N1)2009 }\end{array}$ & $\begin{array}{c}\text { Other or } \\
\text { unsubtyped } \\
\text { Influenza A }\end{array}$ & Negative & Total Tests & $\begin{array}{l}\text { Proportion of } \\
\text { tests } / 100,000\end{array}$ & $\begin{array}{c}\text { Proportion } \\
\text { A(H1N1)2009 } \\
/ 100,000\end{array}$ \\
\hline FLANDERS & 108 & 15 & 367 & 490 & 8,0 & 1,8 \\
\hline Antwerpen & 47 & 5 & 111 & 163 & 9,6 & 2,8 \\
\hline Limburg & 5 & 1 & 43 & 49 & 6,0 & 0,6 \\
\hline Oost-Vlaanderen & 16 & 5 & 85 & 106 & 7,6 & 1,1 \\
\hline Vlaams-Brabant & 33 & 2 & 84 & 119 & 11,3 & 3,1 \\
\hline West-Vlaanderen & 7 & 2 & 44 & 53 & 4,6 & 0,6 \\
\hline WALLONIA & 45 & 12 & 203 & 260 & 7,6 & 1,3 \\
\hline Brabant wallon & 6 & 1 & 35 & 42 & 11,3 & 1,6 \\
\hline Hainaut & 16 & 5 & 73 & 94 & 7,3 & 1,2 \\
\hline Liège & 13 & 2 & 54 & 69 & 6,6 & 1,2 \\
\hline Luxembourg & 3 & 3 & 17 & 23 & 8,8 & 1,1 \\
\hline Namur & 7 & 1 & 24 & 32 & 6,9 & 1,5 \\
\hline BRUSSELS & 23 & 4 & 94 & 121 & 11,7 & 2,2 \\
\hline Unknown & 0 & 0 & 4 & 4 & & \\
\hline Total & 176 & 31 & 668 & 875 & 8,3 & 1,7 \\
\hline
\end{tabular}

During the containment phase clinical criteria included fever $>38^{\circ} \mathrm{C}$, myalgia or general discomfort and cough together with an epidemiological link. Once the circulation of the pandemic virus has been demonstrated in the Belgium population, the epidemiological link was not required anymore to classify a suspected patient as a possible case. As the lab questionnaire was not modified, this information was still mentioned in $77 \%$ of the lab questionnaires.

About $78 \%$ of the patients had fever, cough and myalgia. Dyspnoea was mentioned by $26 \%$ of the confirmed cases. About $30 \%$ of the confirmed cases mentioned an associated symptom and the most frequent ones were diarrhoea, possibly associated with nausea $(11 \%)$, and sore throat $(7 \%)$. 
The classification of all patients following the criteria of the possible case definition allows calculating the sensitivity $(76.4 \% ; 95 \% \mathrm{Cl} 68.5-82.9)$ and specificity $(64.5 \% ; 95 \% \mathrm{Cl} 60.5-$ 68.4 ) of the case definition. If the consequent positive predictive value is quite low, this result offered a negative predictive value of $91.8 \%$ (95\% Cl 88.6-94.2).

In both phases the most frequent epidemiological link was related to travel in an endemic area. The proportion of positive Influenza A(H1N1)2009 was lower among the 'travel related' compared with people coming into 'contact with case' or involved in an 'outbreak' (Table 2) and the proportion is unchanged between both phases.

Table 2. Repartition of the number of tests and results by type of risk, week 17-40/2009, Belgium

\begin{tabular}{|l|r|r|r|r|c|}
\hline & $\mathrm{A}(\mathrm{H} 1 \mathrm{N1}$ )2009 & $\begin{array}{c}\text { Other or un- } \\
\text { subtyped } \\
\text { Influenza A }\end{array}$ & Negative & Tests & $\begin{array}{c}\% \\
\mathrm{~A}(\mathrm{H} 1 \mathrm{~N} 1) 2009\end{array}$ \\
\hline Travel-related & 88 & 29 & 392 & 509 & 17,3 \\
\hline Contact with case & 21 & 1 & 33 & 55 & 38,2 \\
\hline Outbreak Werchter & 13 & 0 & 29 & 42 & 31,0 \\
\hline Outbreak school & 15 & 1 & 3 & 19 & 78,9 \\
\hline No risk & 4 & 0 & 22 & 26 & 15,4 \\
\hline Unknown & 35 & 0 & 189 & 224 & 15,6 \\
\hline Total & $\mathbf{1 7 6}$ & $\mathbf{3}$ & $\mathbf{6 6 8}$ & $\mathbf{8 7 5}$ & $\mathbf{2 0 , 1}$ \\
\hline
\end{tabular}

The country associated with the risk differed nevertheless according to the evolution of the pandemic (Figure 3). During the containment phase, suspected and possible cases returned mainly from North America (35\%) while this place of travel was related in only $2 \%$ of the suspected or possible cases during the mitigation phase. During the latter, suspected cases were mainly associated with travel within Europe or had not travelled. Two peaks in the number of tests in people who did not travel were associated in time with the two outbreaks.

Figure 3. Epidemiological links of tested patients, week 17-40/2009, Belgium

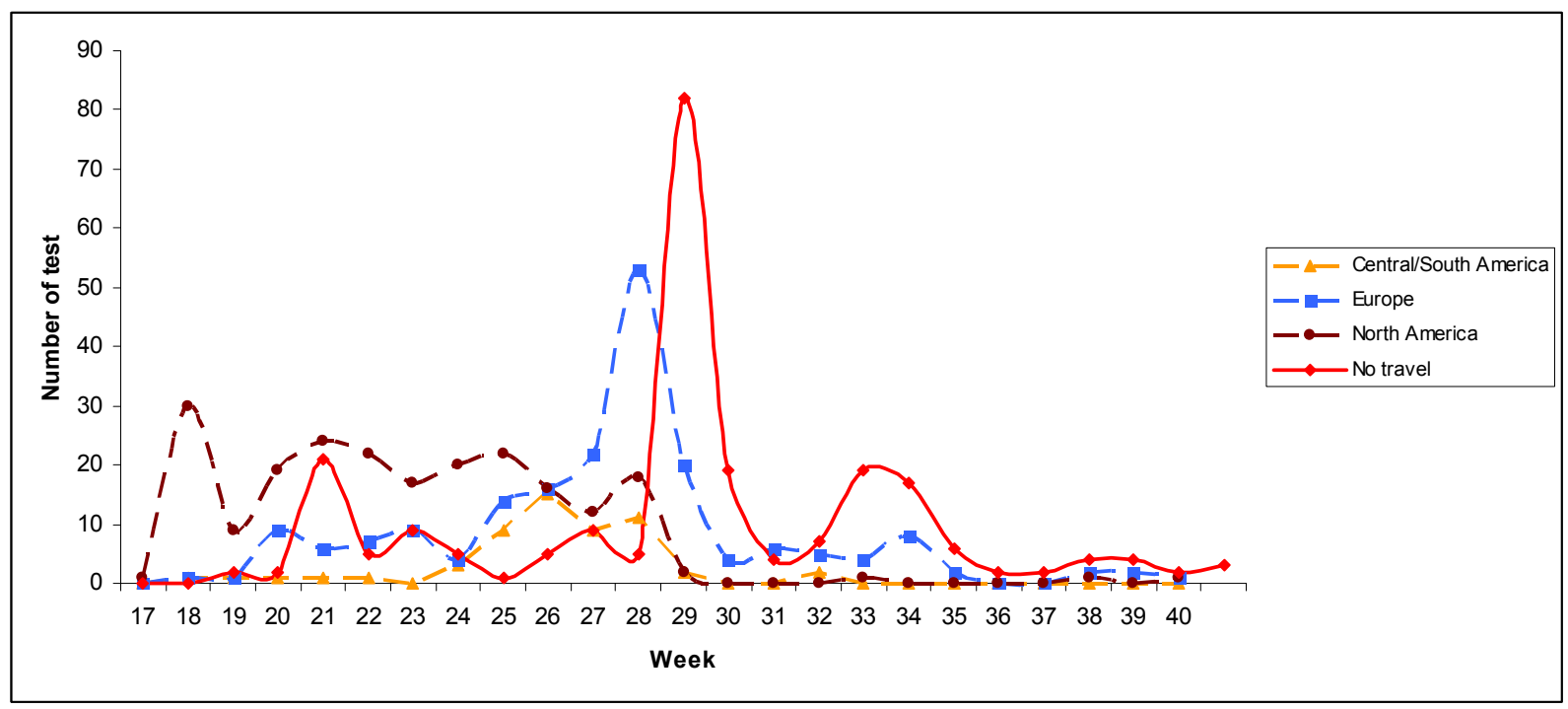


Suspected patients included in the screening returned from more than 50 different countries of all continents. Most of them returned from North America (24.6\%), followed by Europe (22.4\%). About 50 tests were performed for patients back from Mexico none of them was positive for Influenza $A(\mathrm{H} 1 \mathrm{~N} 1) 2009$.

\section{Discussion}

Following the detection of a new Influenza virus in April 2009, Belgium carried out the Influenza Preparedness Plan in order to limit the possible health impact of such a threat. Measures associated with a delaying strategy were implemented in a first phase. The case finding during this phase allowed to implement control measures and was also a useful source for surveillance purposes.

When facing such an event, with so many uncertainties, the reality in the field imposes to adapt some decisions taken in a Preparedness Plan. For surveillance purposes, we soon needed to accept that patients, who did not meet all inclusion criteria of a possible patient, were nevertheless sampled.

Considering the specificity of the case definition, clinical criteria together with epidemiological features indicate that we can be confident about using it to detect most of the potentially infected patients. Nevertheless, considering the transmission way and the possible clinical expressions of an influenza virus, the early detection of any patient seems to be utopia. This reality should be used to adapt control measures put in place in a delaying strategy following the severity of the new virus.

The epidemiology of the initial cases of Influenza A(H1N1)2009 in Belgium was similar to that seen in other countries (6-22).

Most infections with influenza $A(H 1 N 1) 2009$ that occurred in the first period were found in returning travellers. Week 28 was a turning point in the Belgian epidemiology due to 2 local outbreaks related to places where people from various countries participated in a rock festival and a summer language school. The increasing number of cases at that time induced the change in strategy, going from containment phase to mitigation phase. Once the mitigation phase initiated (week 29), the SGP network with integrated epidemiological and virological surveillance has proven particularly valuable in following the spread of the epidemic as it also allows the follow-up of the relative contribution of the different circulating influenza strains (3). Even though the lab diagnosis was not required anymore, samples were still regularly sent to the NIC. These data demonstrated a similar proportion of positive results to the one in the containment phase, indicating that the virus was not circulating more in week 29 than in week 40. This observation raised the question of the real impact of the containment strategy and also highlighted that control measures should be adapted once the severity of a new influenza virus is known. 
As in many other countries, the Influenza $\mathrm{A}(\mathrm{H} 1 \mathrm{~N} 1) 2009$ pandemic strain became the predominant circulating influenza virus within a few weeks of its appearance (6-22). During the mitigation phase, only one seasonal influenza virus was notified.

Some population groups appear more vulnerable to Influenza A(H1N1)2009 pandemic infections than others. The shift in age distribution towards younger age groups, including younger adults and children, compared to seasonal influenza, confirmed previously described data (23-25). Data suggest that the elderly may to some extent be protected from infection (26). The observed shift in age-specific infectivity patterns should influence vaccination priorities (29). The finding of pre-existing antibodies in the elderly, the reduced immune response because of immune senescence in the elderly and greater transmission among children, has prompted the recommendation to include younger age groups for pandemic vaccination (27-29).

In Belgium, the holidays for all schools lasted from 1 July until 31 August. There is some evidence that the start of school holidays reduces influenza transmission and that the return to school slightly accelerates the epidemic (30). This hypothesis requires further in-depth analysis.

The potential impact of pandemics and the occurrence of multiple waves of pandemics in the 20th century underline the importance of active real-time surveillance on a global scale. International collaboration is crucial for the effective exchange of virological, clinical and epidemiological data that will make possible the development of vaccines and treatment protocols and the identification of the best population-based control strategies.

The current epidemic was a national, European and worldwide challenge demonstrating the need in continuous surveillance, fluid collaboration in term of exchange of information and strong coordination in order to facilitate expertise-based decisions.

\section{Conclusions}

Data from this and previous pandemics should provide useful insights for future planning. The efficacy of case finding in such a potentially large and long threat should be evaluated and lessons learnt be optimally used in the frame of the development of further control strategies taking also into account the added value of a European approach.

Facing a potential nationwide public health threat, it was also an enriching experience in which a lot of partners of public health have worked together in a coordinated way. The smooth collaboration between infectious disease control officers, medical epidemiologists, lab collaborators and last but not least, health care workers was the major asset in demonstrating our capacity to tackle new and yet undefined health threats in the future. 


\section{References}

1. Litzroth A, Gutiérrez I, Hammadi S. Influenza A(H1N1)2009 pandemic: Chronology of the events in Belgium. Arch Publ Health 2010; 68(2):48-52

2. Belgian working group on influenza $A(H 1 N 1) v$. Influenza $A(H 1 N 1) v$ virus infections in Belgium, May-June 2009. Euro Surveill 2009 Jul 16;14(28)

3. Van Casteren V, Mertens K, Antoine J, Wanyama S, Thomas I, Bossuyt N. Clinical influenza surveillance of Influenza $\mathrm{A}(\mathrm{H} 1 \mathrm{~N} 1) 2009$ pandemic through the network of Sentinel General Practitioners. Arch Publ Health 2010; 68(2):62-67

4. Gérard C, Brochier B, Quoilin S, Wuillaume Françoise, Van Casteren V, Thomas I. Virological surveillance of Influenza $\mathrm{A}(\mathrm{H} 1 \mathrm{~N} 1) 2009$ pandemic: the roles of the Belgian National Influenza Centre. Arch Public Health 2010; 68(2):68-75

5. Gutiérrez I, Litzroth A, Hammadi S, Van Oyen H, Gerard C, Robesyn E, Bots J, Faidherbe MT, Wuillaume $F$. Community transmission of influenza $A(H 1 N 1) v$ virus at a rock festival in Belgium, 2-5 July 2009. Euro Surveill 2009 Aug 6;14(31)

6. Cullen G, Martin J, O'Donnell J, Boland M, Canny M, Keane E, McNamara A, O'Hora A, Fitzgerald M, Jackson S, Igoe D, O'Flanagan D. Surveillance of the first 205 confirmed hospitalised cases of pandemic H1N1 influenza in Ireland, 28 April - 3 October 2009. Euro Surveill 2009 Nov 5;14(44)

7. Thouillot F, Do C, Balleydier E, Rachou E, Staikowsky F, Morbidelli P, Jacques-Antoine $Y$, Bourde A, Lagrange-Xelot M, Poubeau P, Winer A, Gauzere B, Michault A, Jaffar-Bandjee M, Henrion G, Filleul L, D'Ortenzio E. Preliminary analysis of the pandemic H1N1 influenza on Reunion Island (Indian Ocean): surveillance trends (July to mid-September 2009). Euro Surveill 2009 Oct 22;14(42)

8. Archer B, Cohen C, Naidoo D, Thomas J, Makunga C, Blumberg L, Venter M, Timothy G, Puren A, McAnerney J, Cengimbo A, Schoub B. Interim report on pandemic H1N1 influenza virus infections in South Africa, April to October 2009: epidemiology and factors associated with fatal cases. Euro Surveill 2009 Oct 22;14(42)

9. Oliveira W, Carmo E, Penna G, Kuchenbecker R, Santos H, Araujo W, Malaguti R, Duncan B, Schmidt M; Surveillance Team for the pandemic influenza $A(H 1 N 1) 2009$ in the Ministry of Health. Pandemic H1N1 influenza in Brazil: analysis of the first 34,506 notified cases of influenza-like illness with severe acute respiratory infection (SARI). Euro Surveill 2009 Oct 22;14(42)

10. Gomez J, Munayco C, Arrasco J, Suarez L, Laguna-Torres V, Aguilar P, Chowell G, Kochel T. Pandemic influenza in a southern hemisphere setting: the experience in Peru from May to September, 2009. Euro Surveill. 2009 Oct 22;14(42)

11. McBryde E, Bergeri I, van Gemert C, Rotty J, Headley E, Simpson K, Lester R, Hellard M, Fielding J. Early transmission characteristics of influenza $\mathrm{A}(\mathrm{H} 1 \mathrm{~N} 1) \mathrm{v}$ in Australia: Victorian state, 16 May - 3 June 2009. Euro Surveill. 2009 Oct 22;14(42)

12. La Ruche G, Tarantola A, Barboza P, Vaillant L, Gueguen J, Gastellu-Etchegorry M; epidemic intelligence team at InVS. The 2009 pandemic H1N1 influenza and indigenous populations of the Americas and the Pacific. Euro Surveill. 2009 Oct 22;14(42)

13. Gianella A, Walter A, Revollo R, Loayza R, Vargas J, Roca Y. Epidemiological analysis of the influenza $A(H 1 N 1) v$ outbreak in Bolivia, May-August 2009. Euro Surveill. 2009 Sep 3;14(35)

14. Gilsdorf A, Poggensee G; Working Group Pandemic Influenza A(H1N1)v. Influenza A(H1N1)v in Germany: the first 10,000 cases. Euro Surveill. 2009 Aug 27;14(34)

15. Baker MG, Wilson N, Huang QS, Paine S, Lopez L, Bandaranayake D, Tobias M, Mason K, Mackereth GF, Jacobs M, Thornley C, Roberts S, McArthur C. Pandemic influenza A(H1N1)v in New Zealand: the experience from April to August 2009. Euro Surveill. 2009 Aug 27;14(34)

16. Ciblak MA, Albayrak N, Odabas Y, Basak Altas A, Kanturvardar M, Hasoksuz M, Sucakli B, Korukluoglu G, Bal E, Ertek M, Badur S. Cases of influenza A(H1N1)v reported in Turkey, May-July 2009. Euro Surveill. 2009 Aug 13;14(32). pii: 19304. Erratum in: Euro Surveill. 2009;14(33) 
17. Castro-Jiménez MA, Castillo-Pabón JO, Rey-Benito GJ, Pulido-Domínguez PA, Barbosa-Ramírez J, Velandia-Rodriguez DA, Angulo-Martínez ES; Virology Group; Communicable Diseases Surveillance Group. Epidemiologic analysis of the laboratory-confirmed cases of influenza $A(H 1 N 1) v$ in Colombia. Euro Surveill. 2009 Jul 30;14(30):19284

18. Influenza $A(H 1 N 1) v$ investigation teams, Levy-Bruhl $D$, Vaux S. Modified surveillance of influenza $A(H 1 N 1) v$ virus infections in France. Euro Surveill. 2009 Jul 23;14(29)

19. Lytras T, Theocharopoulos G, Tsiodras S, Mentis A, Panagiotopoulos T, Bonovas S; influenza surveillance report group. Enhanced surveillance of influenza $A(H 1 N 1) v$ in Greece during the containment phase. Euro Surveill. 2009 Jul 23;14(29).

20. Hahné S, Donker T, Meijer A, Timen A, van Steenbergen J, Osterhaus A, van der Sande M, Koopmans $M$, Wallinga J, Coutinho R; Dutch New Influenza A(H1N1)v Investigation Team. Epidemiology and control of influenza $A(H 1 N 1) v$ in the Netherlands: the first 115 cases. Euro Surveill. 2009 Jul 9;14(27)

21. Rizzo C, Declich S, Bella A, Caporali MG, Lana S, Pompa MG, Vellucci L, Salmaso S. Enhanced epidemiological surveillance of influenza $A(H 1 N 1) v$ in Italy. Euro Surveill. 2009 Jul 9;14(27)

22. Shimada T, Gu Y, Kamiya H, Komiya N, Odaira F, Sunagawa T, Takahashi H, Toyokawa T, Tsuchihashi $\mathrm{Y}$, Yasui $\mathrm{Y}$, Tada $\mathrm{Y}$, Okabe N. Epidemiology of influenza $A(\mathrm{H} 1 \mathrm{~N} 1) \mathrm{v}$ virus infection in Japan, May-June 2009. Euro Surveill. 2009 Jun 18;14(24)

23. Baker M, Kelly H, Wilson N. Pandemic H1N1 influenza lessons from the southern hemisphere. Euro Surveill. 2009 Oct 22;14(42)

24. Turbelin C, Pelat C, Boëlle PY, Lévy-Bruhl D, Carrat F, Blanchon T, Hanslik T. Early estimates of 2009 pandemic influenza $A(H 1 N 1)$ virus activity in general practice in France: incidence of influenza-like illness and age distribution of reported cases. Euro Surveill. 2009 Oct 1;14(39)

25. Pérez-Trallero E, Piñeiro L, Vicente D, Montes M, Cilla G. Residual immunity in older people against the

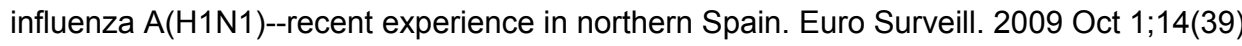

26. Vaillant L, La Ruche G, Tarantola A, Barboza P; epidemic intelligence team at InVS. Epidemiology of fatal cases associated with pandemic H1N1 influenza 2009. Euro Surveill. 2009 Aug 20;14(33)

27. Towers S, Feng Z. Pandemic H1N1 influenza: predicting the course of a pandemic and assessing the efficacy of the planned vaccination programme in the United States. Euro Surveill. 2009 Oct 15;14(41):19358

28. Miller MA, Viboud C, Balinska M, Simonsen L. The signature features of influenza pandemics-implications for policy. N Engl J Med. 2009 Jun 18;360(25):2595-8

29. Miller MA, Viboud C, Olson DR, Grais RF, Rabaa MA, Simonsen L. Prioritization of influenza pandemic vaccination to minimize years of life lost. J Infect Dis. 2008 Aug 1;198(3):305-11

30. Sypsa V, Hatzakis $A$. School closure is currently the main strategy to mitigate influenza $A(H 1 N 1) v$ : a modeling study. Euro Surveill. 2009 Jun 18;14(24) 